\title{
Large infrequent rain events dominate the hydroclimate of Rapa Nui (Easter Island)
}

\author{
Nathan J. Steiger ${ }^{1,2} \oplus \cdot$ William J. D'Andrea ${ }^{1} \cdot$ Jason E. Smerdon ${ }^{1} \cdot$ Raymond S. Bradley $^{3}$
}

Received: 18 April 2021 / Accepted: 7 January 2022 / Published online: 22 January 2022

(c) The Author(s) 2022

\begin{abstract}
The history of the Polynesian civilization on Rapa Nui (Easter Island) over the Common Era has come to exemplify the fragile relationship humans have with their environment. Social dynamics, deforestation, land degradation, and climatic shifts have all been proposed as important parts of the settlement history and societal transformations on Rapa Nui. Furthermore, climate dynamics of the Southeast Pacific have major global implications. While the wetlands of Rapa Nui contain critical sedimentological archives for reconstructing past hydrological change on the island, connections between the island's hydroclimate and fundamental aspects of regional climatology are poorly understood. Here we present a hydroclimatology of Rapa Nui showing that there is a clear seasonal cycle of precipitation, with wet months receiving almost twice as much precipitation as dry months. This seasonal cycle can be explained by the seasonal shifts in the location and strength of the climatological south Pacific subtropical anticyclone. For interannual precipitation variability, we find that the occurrence of infrequent, large rain events explains $92 \%$ of the variance of the observed annual mean precipitation time series. Approximately one third (33\%) of these events are associated with atmospheric rivers, $21 \%$ are associated with classic cold-front synoptic systems, and the remainder are characterized by cut-off lows and other synoptic-scale storm systems. As a group, these large rain events are most strongly controlled by the longitudinal position of the south Pacific subtropical anticyclone. The longitudinal location of this anticyclone explains $21 \%$ of the variance in the frequency of large rain events, while the remaining variance is left unexplained by any other major atmosphere-ocean dynamics. We find that over the observational era there appears to be no linear relationship between the number of large rain events and any other major climate phenomena. With the south Pacific subtropical anticyclone projected to strengthen and expand westward under global warming, our results imply that Rapa Nui will experience an increase in the number of dry years in the future.
\end{abstract}

Keywords Rapa Nui · Easter Island · Drought $\cdot$ Rain $\cdot$ Climatology $\cdot$ Hydroclimate

\section{Introduction}

The island of Rapa Nui (Easter Island; $27^{\circ} 6^{\prime} \mathrm{S}, 109^{\circ} 21^{\prime}$ $\mathrm{W})$ is located in the southeastern Pacific Ocean. It has a subtropical climate, experiencing comparatively little temperature variation and prevailing easterly winds (Fig. 1a,b).

Nathan J. Steiger

nsteiger@1deo.columbia.edu

1 Lamont-Doherty Earth Observatory, Columbia University, Palisades, NY, USA

2 Institute of Earth Sciences, Hebrew University of Jerusalem, Jerusalem, Israel

3 Climate System Research Center, Department of Geosciences, University of Massachusetts Amherst, Amherst, MA, USA
The climate of the southeastern Pacific Ocean more broadly is controlled by a persistent high-pressure system or anticyclone. Like other subtropical anticyclones, it resides within a region of subsidence driven by the Hadley circulation, and the anticyclone is fundamentally maintained through monsoonal heating of the continent to its east (here, South America) (Seager et al. 2003). To the west of this anticyclone can be found the eastern-most limb of the South Pacific Convergence Zone (SPCZ), a band of precipitation that stretches diagonally from Rapa Nui up towards the equator north of Papua New Guinea (Fig. 1c). Moist, northeasterly trade winds collide with southwesterly Rossby waves to produce this band of precipitation (Kiladis et al. 1989; Vincent 1994; Van Der Wiel et al. 2016). The diagonal Northwest-Southeast orientation of the SPCZ and its relative strength and variability are largely determined by the 


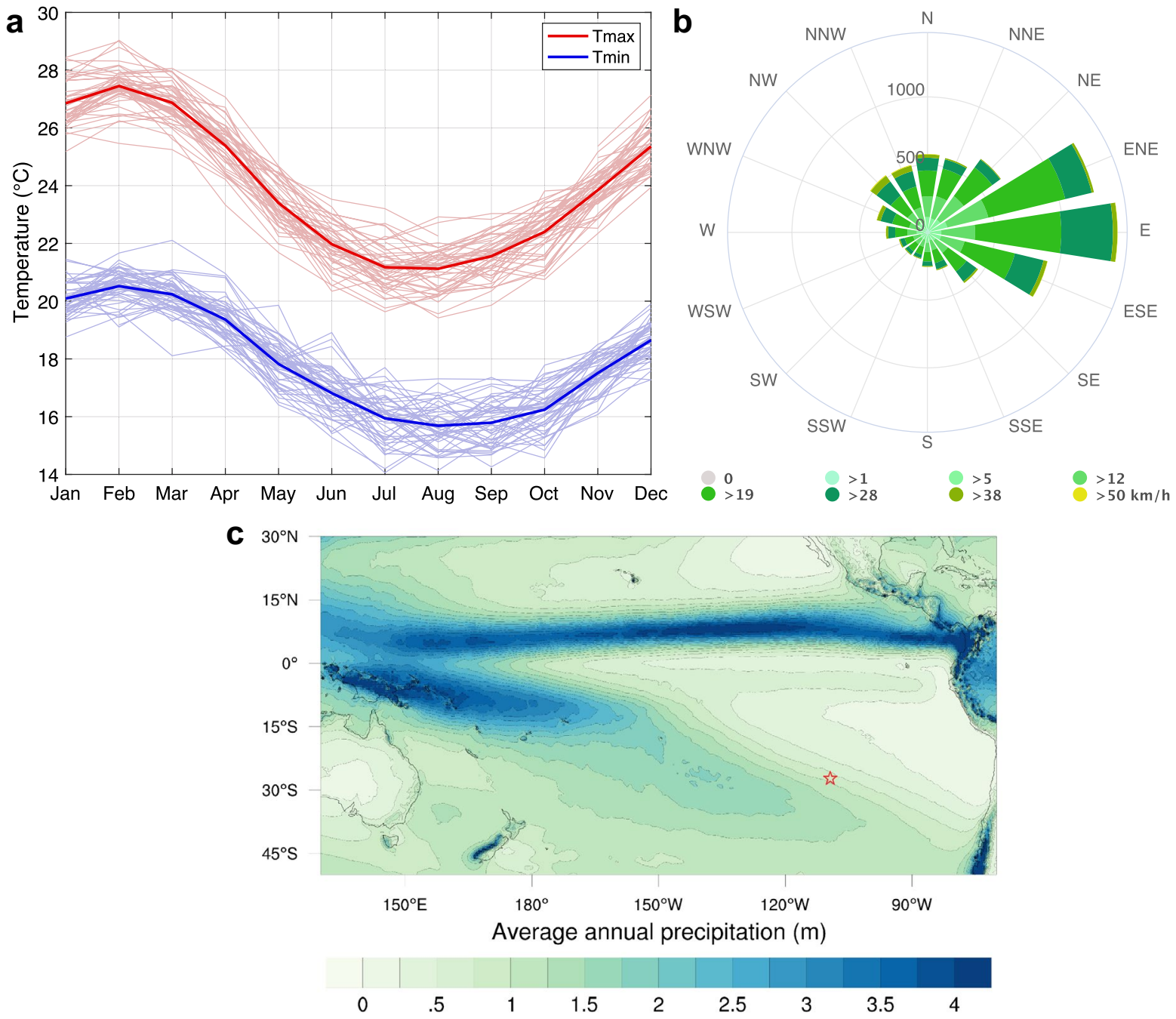

Fig. 1 Climatic features of Rapa Nui. a Monthly average maximum and minimum temperatures on Rapa Nui (Mataveri International Airport) from 1970 to 2017 (Centro de Ciencias del Clima y la Resiliencia 2019). Light-colored lines are individual years, dark-colored lines are the mean of all years. b Wind rose for Rapa Nui, indicating wind direction, speed, and frequency, with the radial coordinate in units

strength of the south Pacific anticyclone, which in turn is related to variability in ocean circulation, tropical heating, and the sea surface temperature distribution across the South Pacific (Seager et al. 2003; Van Der Wiel et al. 2016; Fahad et al. 2021). The easternmost position of the SPCZ is also set by the position of the south Pacific anticyclone, the easterly trade winds (Lintner and Neelin 2008), and the atmosphere's response to the presence of the Andes Mountains (Takahashi and Battisti 2007). Besides understanding the hydroclimate of Rapa Nui for its own sake, these regional dynamics have critical connections to global climate, including the Hadley circulation and cloud feedbacks over the south Pacific. These phenomena are essential to understanding tropical dynamics and the global climate sensitivity to radiative forcing of hours per year. Based on reanalysis wind data from 1979 to 2017 (Copernicus Climate Change Service 2019). c Average annual precipitation over the central and south Pacific Ocean from 1979 to 2017 (Copernicus Climate Change Service 2019). The location of Rapa Nui is indicated by a red star

(Pierrehumbert 1995; Bony and Dufresne 2005; Cai et al. 2012; He et al. 2017).

While there is a general understanding of the major dynamical features of the southeastern Pacific region, there exists no comprehensive characterization of the hydroclimatology specifically over Rapa Nui. A daily precipitation record from Mataveri International Airport on Rapa Nui that begins in 1955 nevertheless provides an opportunity to investigate teleconnections and regional climatic controls on precipitation patterns over the island on seasonal to interannual timescales. To our knowledge, only a single study has taken advantage of this precipitation record to evaluate the impacts of atmospheric dynamics (specifically, the El Niño-Southern Oscillation (ENSO) phenomenon) on 
interannual precipitation variability over Rapa Nui (Genz and Hunt 2003).

Understanding the controls on precipitation over various timescales is important for both the current and historical climate on Rapa Nui. The island has become a major ecotourism destination and is undergoing rapid development that poses numerous environmental threats (Figueroa and Rotarou 2016). Daily flights from Santiago, Chile to Rapa Nui brought approximately 69,000 visitors in 2017 (the last year of record keeping by the Chilean National Forest Corporation), up from approximately 36,000 in 2007 (Corporación Nacional Forestal 2020). As a remote island with variable precipitation and increasing freshwater demands, understanding the vulnerabilities of the island to changing climate is important for sustainable planning. The uncertainties concerning how precipitation patterns will respond to future anthropogenic global warming add an additional layer of complexity to this problem.

Paleoclimate and paleoecological records from wetland and lake sediments along the west coast of South America (Moreno et al. 1999; Jenny et al. 2003; Valero-Garcés et al. 2005; Lamy et al. 2010; Margalef et al. 2013; Kilian and Lamy 2012) and the island of Rapa Nui (Azizi and Flenley 2008; Mann et al. 2008; Sáez et al. 2009; Margalef et al. 2013) document large changes in the hydroclimate of these regions that are not well captured in modern observational records. For instance, centennial-scale hydroclimate changes have been inferred for the period of human occupation of Rapa Nui (beginning circa 1000 CE) (Rull et al. 2018; Cañellas-Boltà et al. 2013) and in the early Holocene (Sáez et al. 2009), while even greater amplitude fluctuations have been inferred at multi-millennial time scales extending back 27,000 years (Sáez et al. 2009). These hydroclimate changes are presumably tied to changes in atmospheric circulation patterns over the southeastern Pacific. Dynamical explanations for these hydroclimate shifts are mostly speculative and have included the influence of ENSO (Mann et al. 2008; Stenseth and Voje 2009), changes in the trade winds and Walker Circulation (Bridgman 1983; McCall 1993), changes to the south Pacific anticyclone, changes in the SPCZ, and changes in the strength and latitudinal position of the westerly storm track (Sáez et al. 2009; Cañellas-Boltà et al. 2013). These studies are important for their implications for regional and global-scale climatological changes and can also provide the climate context for historical changes in Rapanui culture. This culture flourished on the island during the early to mid second millennium CE, and the Rapa Nui people implemented numerous strategies to mitigate the impacts of drought (Stevenson et al. 2002; Ladefoged et al. 2013; Brosnan et al. 2019). A better understanding of the variability of precipitation on the island therefore promises to shed light on the history of the Rapanui people (McCall
1993; Mann et al. 2008; Mieth and Bork 2010; Rull et al. 2018).

\section{Data}

We use daily observational precipitation data collected on Rapa Nui (Easter Island) at the Mataveri International Airport from 1955 to the present (Centro de Ciencias del Clima y la Resiliencia 2019). Our analyses include all of the data up to and including 2017; all data for the year 1990 are reported as missing.

Output from the ERA5 reanalysis data (Copernicus Climate Change Service 2019) is used at $1^{\circ}$ resolution. In particular we use the following daily variables: accumulated precipitation, $2 \mathrm{~m}$ temperature, $10 \mathrm{~m}$ wind speed, mean sea level pressure, $500 \mathrm{hPa}$ geopotential height, and integrated water vapor transport. ERA5 is available beginning in 1979 and is analyzed here through the year 2017. While the timing of rain events is well-captured by ERA5, the amount of precipitation on Rapa Nui is systematically underestimated by ERA5 relative to the observations. ERA5 underestimates monthly precipitation by an average of $22 \mathrm{~mm}$. This underestimation was confirmed in the original, non-interpolated $0.25^{\circ}$ resolution of the ERA5 data and has been shown to exist in ERA5 in other locations (Hu and Franzke 2020). This underestimation is due mostly to the underestimation of the magnitude of precipitation extremes, a common weather and climate model bias (O'Gorman and Schneider 2009). We therefore focus our precipitation analysis on the observational data, except when spatial patterns of precipitation are shown.

\section{Features and dynamical causes of the seasonal cycle of precipitation}

Precipitation on Rapa Nui follows a seasonal cycle of comparatively wet and dry months, Fig. 2a, with the wettest months receiving nearly twice as much precipitation as the driest months. In order to objectively classify months of the seasonal cycle, we partition the twelve values of monthly mean precipitation on the island into three clusters using a $k$-means clustering algorithm. $k$-means clustering is a datapartitioning technique that groups data points into $k$ clusters according to the grouping that minimizes the distance between within-group data points and the group means; this produces clusters of data points that are most similar to each other. Based on classical subtropical climate regimes, we interpret the three clusters as dry (January, February, October, November, December), transition (March, August, September), and wet (April, May, June, July) seasons, Fig. 2a. 

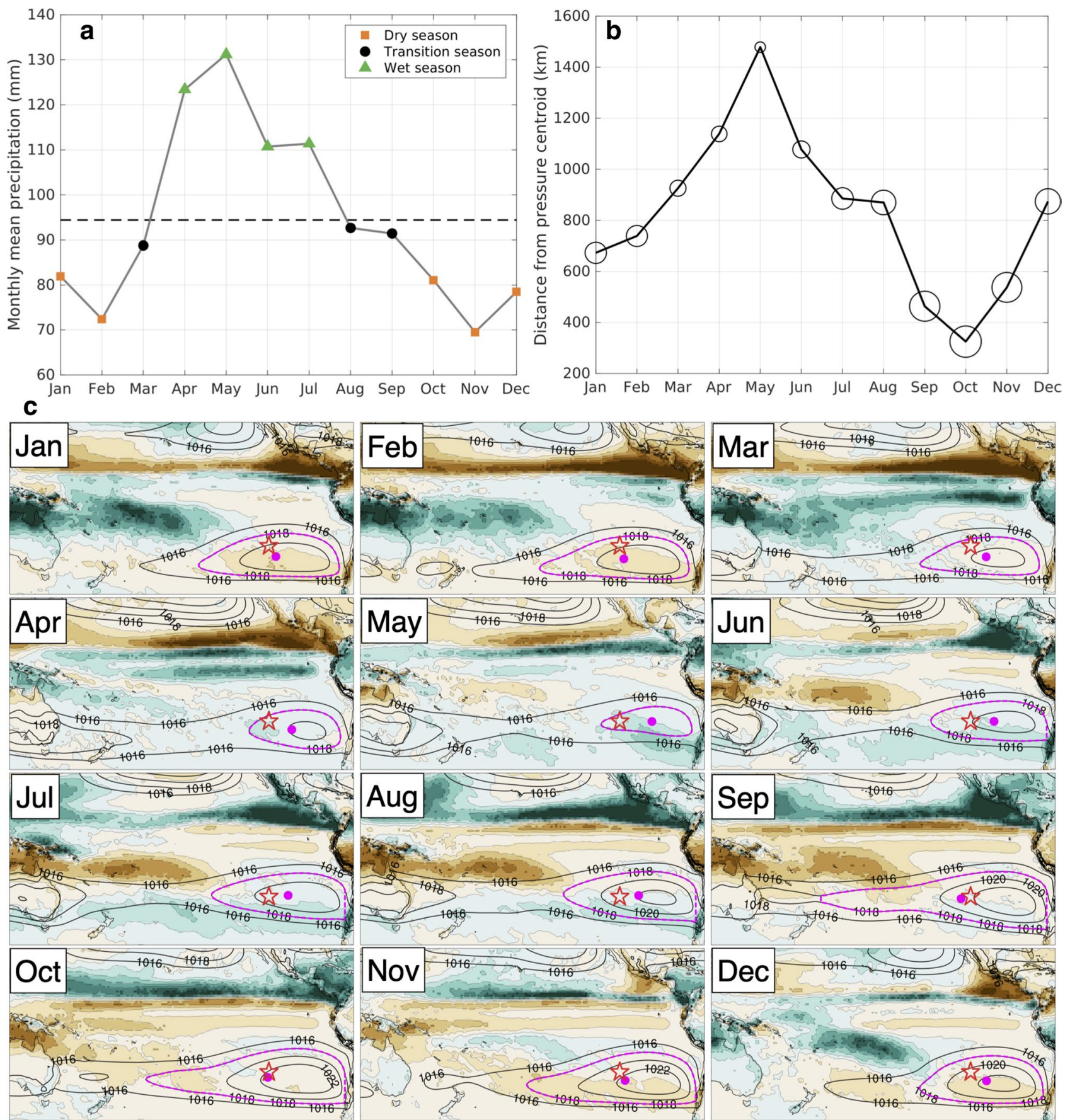

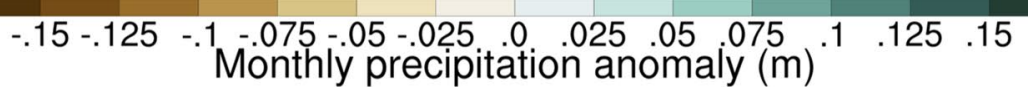

Fig. 2 Climatological precipitation. a The average monthly precipitation on Rapa Nui (Easter Island) based on observational data from the years 1955-2017. Dashed line indicates the average over all months. Precipitation seasons (dry, transition, wet) were determined through a cluster analysis (see text). b The average distance of Rapa Nui from the south Pacific subtropical anticyclone (pressure centroids) for each month (see magenta contours and dots in panel c, along with a further explanation). The size of the circles for each month are scaled to the maximum pressure value of each anticyclone. $\mathbf{c}$ The average monthly precipitation anomaly (colors) and the average monthly mean sea level pressure (line contours in $\mathrm{hPa}$ from 1016-1022 $\mathrm{hPa}$ ) from ERA5 reanalysis (Copernicus Climate Change Service 2019) over the years 1979-2017. Red stars indicate the location of Rapa Nui. Magenta dotted lines follow the $1018 \mathrm{hPa}$ contour in the South Pacific and the magenta dots show the location of the centroid (area-weighted center of mass) of the $1018 \mathrm{hPa}$-enclosed regions. These indicate the size and location of each month's climatological anticyclone 
Dynamically, the seasonal cycle of precipitation in the South Pacific can be explained by seasonal shifts in subtropical circulation. Austral spring and summer (Sep-Feb) see an increase in the strength of the subtropical anticyclone and a reduction in storms, while austral fall and winter (Mar-Aug) see an increase in the number of storms and a reduction in the strength of the subtropical anticyclone (Seager et al. 2003). For Rapa Nui, we find that the strength of the south Pacific anticyclone and the distance of the anticyclone from the island best explains the seasonal cycle of precipitation (e.g., anticyclone distance better explains the seasonal cycle than local sea level pressure). The shape of the seasonal cycle of precipitation, Fig. 2a, closely tracks the distance of the subtropical anticyclone from Rapa Nui, Fig. 2b. Additionally, the wet months have weak maximum anticyclone pressures while dry months have strong maximum anticyclone pressures (indicated by circle sizes in Fig. 2b). We interpret Fig. $2 \mathrm{~b}$ as indicating that when the subtropical anticyclone is weakest and farthest away, more storms are allowed to pass over Rapa Nui, consistent with the general dynamics of the subtropical Southern Hemisphere described in Seager et al. (2003). (While the month of December has an anticyclone that is anomalously far from Rapa Nui, we note that December is in the summer dry season when there are in general fewer storms.) This dynamical explanation can be illustrated in greater spatial detail in Fig. 2c, which shows the average monthly precipitation anomaly and the average monthly mean sea level pressure field. Figure 2c also illustrates the features of the subtropical anticyclone by highlighting the $1018 \mathrm{hPa}$ contour and showing the location

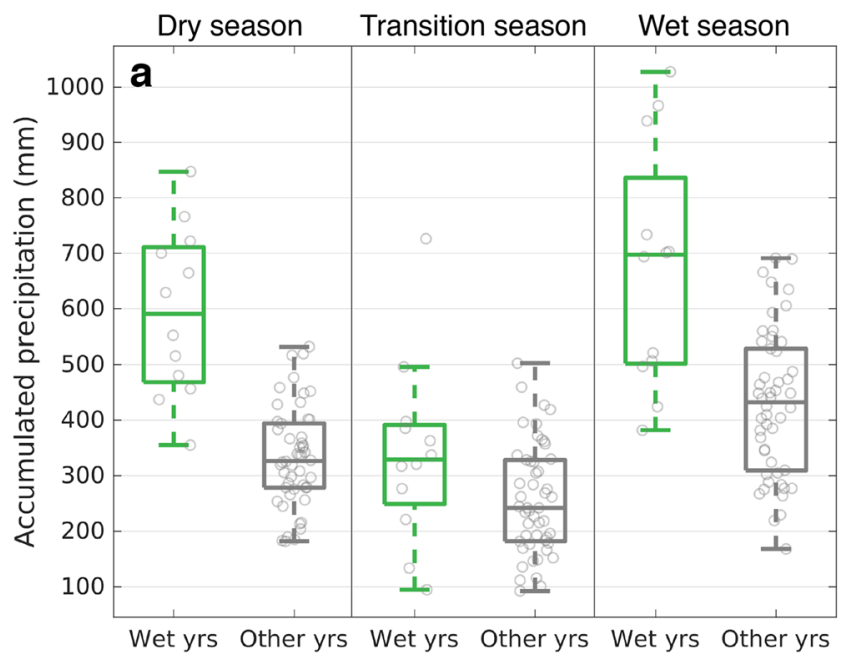

Fig. 3 Seasonality of precipitation for wet and dry years. a Observational accumulated precipitation for each season (dry, transition, wet) over $n=62$ years indicated by gray circles, grouped according to wet years $(n=12)$ and all other years $(n=50)$ and summarized by green and gray box plots. Year groupings were determined based on a $k$-means cluster analysis. The two distributions in the dry and wet of the pressure centroid (center of mass of each highlighted region, with each grid point also weighted by its grid box area), as used in the calculations shown in Fig. $2 b$.

\section{Seasonality of wet and dry years}

If the wet season receives nearly twice as much rain as the dry season, are wet or dry years largely determined by how much rain falls in the wet season? To explore this question, we first use $k$-means clustering to partition the annual mean precipitation time series into three group clusters corresponding to wet years, intermediate years, and dry years. Figure 3a separates out wet years from all other years (intermediate years plus dry years) for each precipitation season: dry, transition, and wet. This figure panel shows that wet years can have either a wet dry season, a wet wet season, or both. Figure $3 \mathrm{~b}$ similarly contrasts dry years against all other years (intermediate years plus wet years) and it shows that dry years can be dry in any season. Both panels of Fig. 3 show that wet or dry years are not determined by the wet season or any other single season, but are reflective of the combined influence of every season. This is also supported by a simple correlation analysis between the annual precipitation and each season's precipitation: the correlation with the dry season is 0.70 , the correlation with the transition season is 0.57 , and the correlation with the wet season is $0.73(n=62$ for all correlations); correlations are best for the dry and wet seasons, but no particular season is anomalously correlated with the annual total.

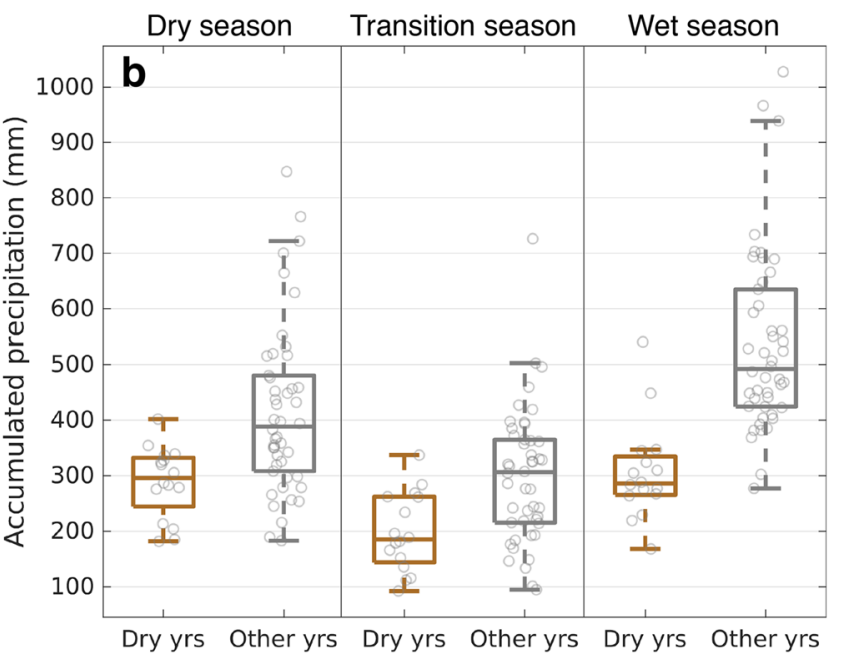

season groupings pass a two-sample $\mathrm{K}-\mathrm{S}$ test $(\alpha=0.05)$, while the two distributions in the transition season grouping do not. b Same as in (a), but with a grouping of dry years alone $(n=16)$ and all other years $(n=46)$, summarized by brown and gray box plots. For this panel all groupings pass a two-sample $\mathrm{K}-\mathrm{S}$ test $(\alpha=0.05)$ 


\section{Rain event characterization}

We next seek to understand the specific ways in which it rains on Rapa Nui. We again use a $k$-means clustering to partition the daily precipitation data into four clusters, but in this case use an $L 1$ distance metric (sum of absolute differences), instead of the common default $L 2$ distance metric (squared Euclidean distance) which we have used in our previous analyses. We adopt the $L 1$ metric because the daily precipitation data contain many outliers that would be heavily weighted by an $L 2$ distance metric. The use of four clusters with an $L 1$ distance metric produces a cluster comprising no rain and negligible rain event days ("Cluster 1" $\leq 1 \mathrm{~mm}$ ), a cluster of moderate rain event days $(1 \mathrm{~mm}<$ "Cluster 2" $\leq 6 \mathrm{~mm})$, and two clusters of large rain event days $(6 \mathrm{~mm}<$ "Cluster 3 " $\leq 20 \mathrm{~mm})$ and $(20$ $\mathrm{mm}<$ "Cluster 4" $\leq 153 \mathrm{~mm}$ ), see Fig. 4a,b. We note that
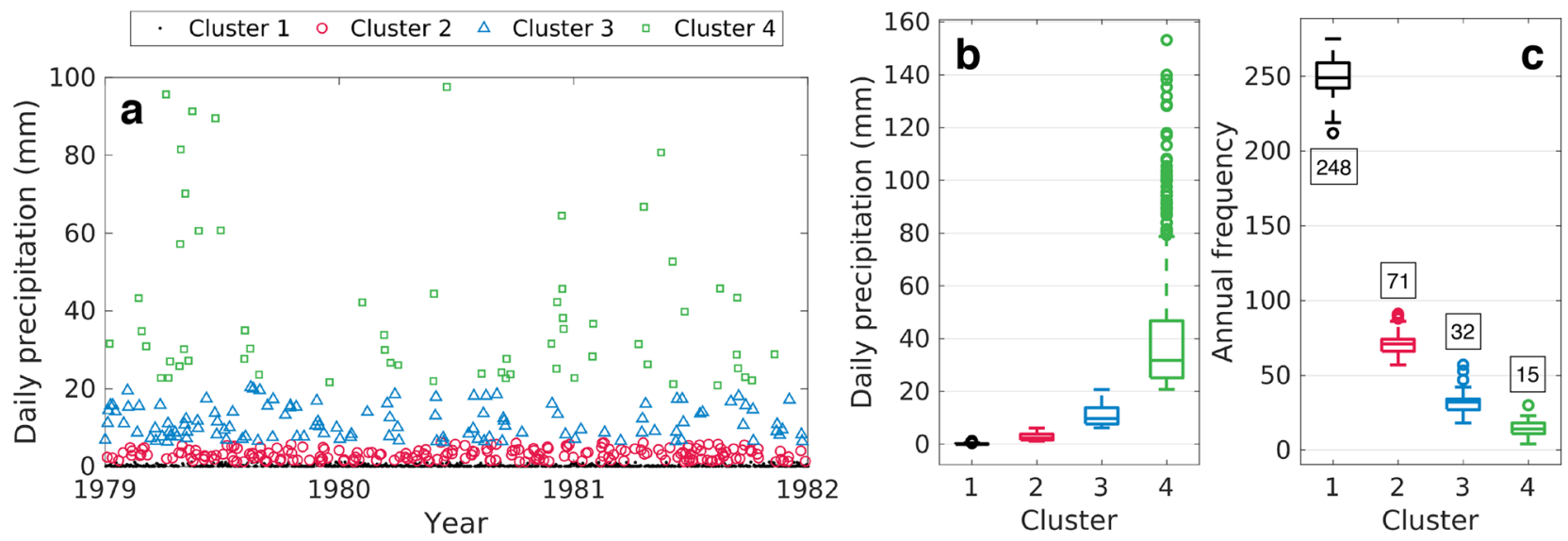

----Cluster $1 \rightarrow$ Cluster $2 \leadsto$ Cluster $3 \multimap-$ Cluster 4
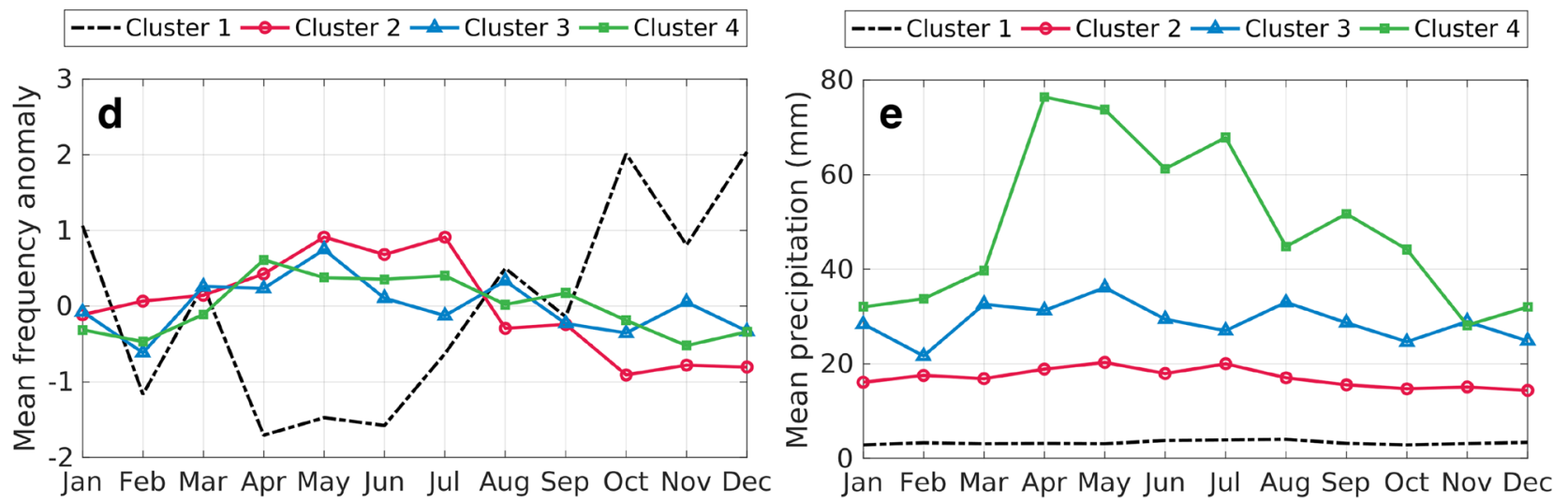

Fig. 4 Precipitation cluster analysis. a An example of three years of observational daily precipitation, plotted by cluster number. b Box plot summaries of all daily precipitation values by cluster number. Clustered observational data is over the period of ERA5 overlap, 1979-2017. Boxes show the 25th, 50th, and 75th percentiles, whiskers extend to the most extreme data points not considered outliers, and outliers are indicated by circles. c Distribution of the annual frequency of daily rain events of each cluster type. Box plots show the determining the number of clusters to use is not a fully objective choice. In the partitioning we seek the fewest possible clusters that retain consistent features within each cluster; the use of three clusters was therefore rejected because the convention yielded a cluster with the lowest centroid value that contained a mix of days with both no rain and moderate rain.

Features of the four data clusters, numbered 1 through 4 according to increasing cluster group values, are shown in Fig. 4. Figure 4a illustrates the clustering in three years of representative daily data and Fig. $4 \mathrm{~b}$ uses box plots to summarize the values of all the daily data for each cluster. Cluster 1 occurs the most frequently with an average of 248 occurrences each year, while Cluster 4 is the least frequent with an average of 15 occurrences each year (Fig. 4c). Each cluster has a seasonal cycle in the frequency of occurrences (Fig. 4d), though the differences between months are fairly small, with a difference of up to about 2-4 occurrences same statistical properties as in (b). The average frequency of each cluster is indicated by the boxed numbers (so for example, there are an average of $n=15$ Cluster 4 events each year). d The seasonal cycle of cluster frequency, shown as anomalies with respect to each cluster's annual average frequency [same annual average values as boxed numbers in (c)]. $\mathbf{e}$ The seasonal cycle of mean precipitation of each cluster 
depending on the cluster and the seasons in question. The changes in the seasonal occurrence of cluster events is nevertheless much more pronounced for Cluster 4 when the contribution to the amount of precipitation is accounted for in this cluster (Fig. 4e). Moreover, Fig. 4e indicates that the seasonal cycle in precipitation on Rapa Nui is mostly controlled by the seasonal cycle in unusually large rain events characterized by Cluster 4 .

The four clusters are further characterized in Fig. 5, showing the total annual precipitation and the annual precipitation of each cluster. The Pearson correlation $(r)$ between the 1-4 cluster time series and total annual precipitation is 0.15 , $0.02,0.65$, and 0.96 , respectively. The large and dominant correlation between Cluster 4 and total precipitation implies an explained variance within a linear regression framework of $92 \%$ and therefore a time history of total precipitation on Rapa Nui that can be almost entirely explained by large, infrequent rain events. Wet or dry years could therefore be the result of Cluster 4 events that either change in number and/or magnitude. We find that the average Cluster 4 event has relatively small year-to-year changes in magnitude (a standard deviation of $6.7 \mathrm{~mm}$ ) while the number of Cluster 4 events each year ranges from 4 to 30 . The number of Cluster 4 events each year has a correlation of 0.91 with total annual precipitation. It is therefore the annual frequency of Cluster 4 events that determines whether the year is wet or dry on Rapa Nui.

Average spatial characteristics of each cluster are represented in Fig. 6 by composites of precipitation and mean sea level pressure for each of the clusters. These composites indicate that there is no particularly strong feature characterizing Clusters 1 and 2, while Clusters 3 and 4 are characteristic of synoptic storm systems. Cluster 4 is amplified relative to Cluster 3, and the synoptic system is displaced more northward with a strong area of high pressure to the south.
Note that these composites are averages over hundreds to thousands of events (see Fig. 6 caption).

If we move beyond the averaged conditions shown in Fig. 6, we see that the key Cluster 4 events can actually be caused by a wide variety of synoptic phenomena. We first look at the correspondence between these events and atmospheric rivers, which are known to sometimes cause extreme sea level rise on Rapa Nui (Carvajal et al. 2021). We use the atmospheric river algorithm tested in Reid et al. (2020) to calculate all atmospheric rivers in the Southern Hemisphere in ERA5 for the period of our analyses (19792017). Specifically, we calculate the daily integrated water vapor transport and then use the following parameter and geometric conditions for identifying atmospheric rivers: (1) We use an integrated water vapor transport threshold of 250 $\mathrm{kg} \mathrm{m}^{-1} \mathrm{~s}^{-1}$ that each atmospheric river must exceed. (2) The major axis of the atmospheric river must be greater than $2000 \mathrm{~km}$. (3) The length-to-width ratio of the atmospheric river must be greater than 2. (4) The angle of orientation of the atmospheric river must be greater than $10^{\circ}$ so as to rule out zonal structures like the intertropical convergence zone. Using the Reid et al. (2020) algorithm with its associated criteria, we find that atmospheric rivers are associated with $33 \%$ of Cluster 4 events.

In order to explore the spatial features of these atmospheric rivers, we use a self-organizing map algorithm (as in Steiger et al. (2021)) to partition the integrated water vapor transport fields into fundamental spatial patterns during Cluster 4 atmospheric-river events. Self-organizing maps are a neural network-based cluster analysis (Kohonen 1998) that has been widely used in the climate sciences to describe the continuum of climate patterns within a dataset (e.g., Johnson et al. (2008); Horton et al. (2015)). As in k-means cluster analysis, one first specifies a preset number of patterns and then the self-organizing map algorithm creates
Fig. 5 Annual precipitation time series. The annual precipitation of each cluster compared against the total precipitation for the years of overlap with ERA5, 1979-2017. The year 1990 is missing in the observational data

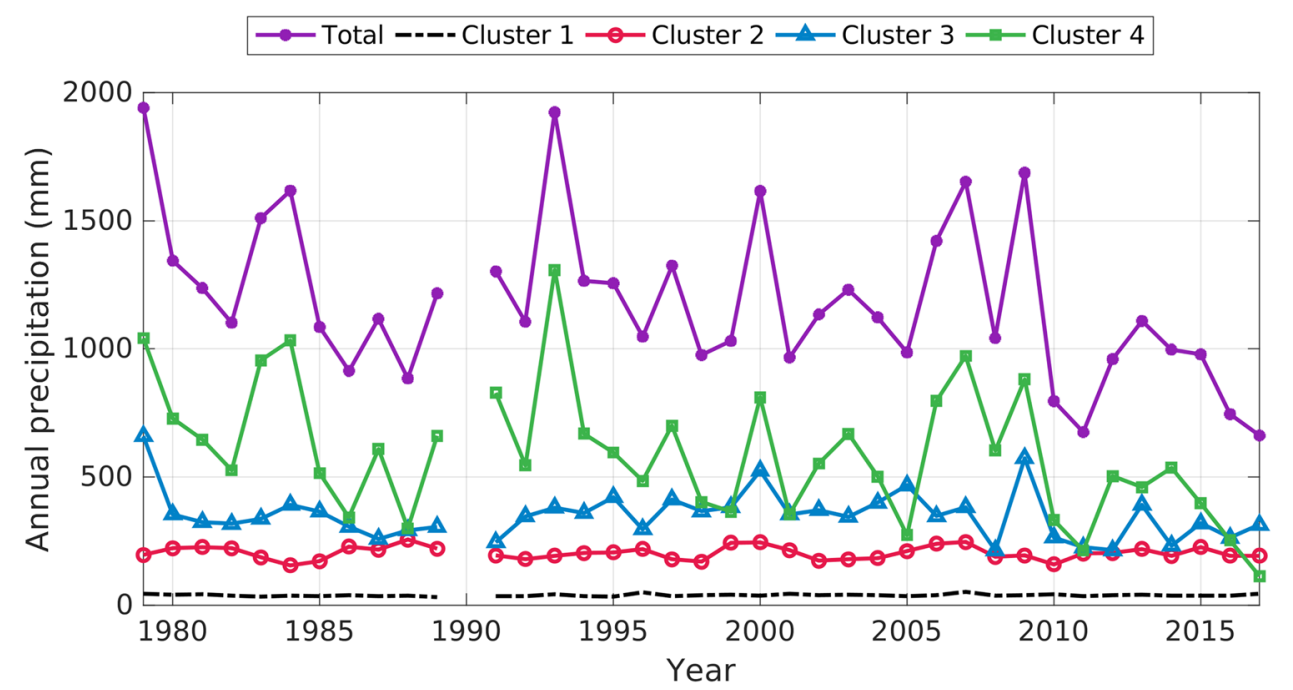



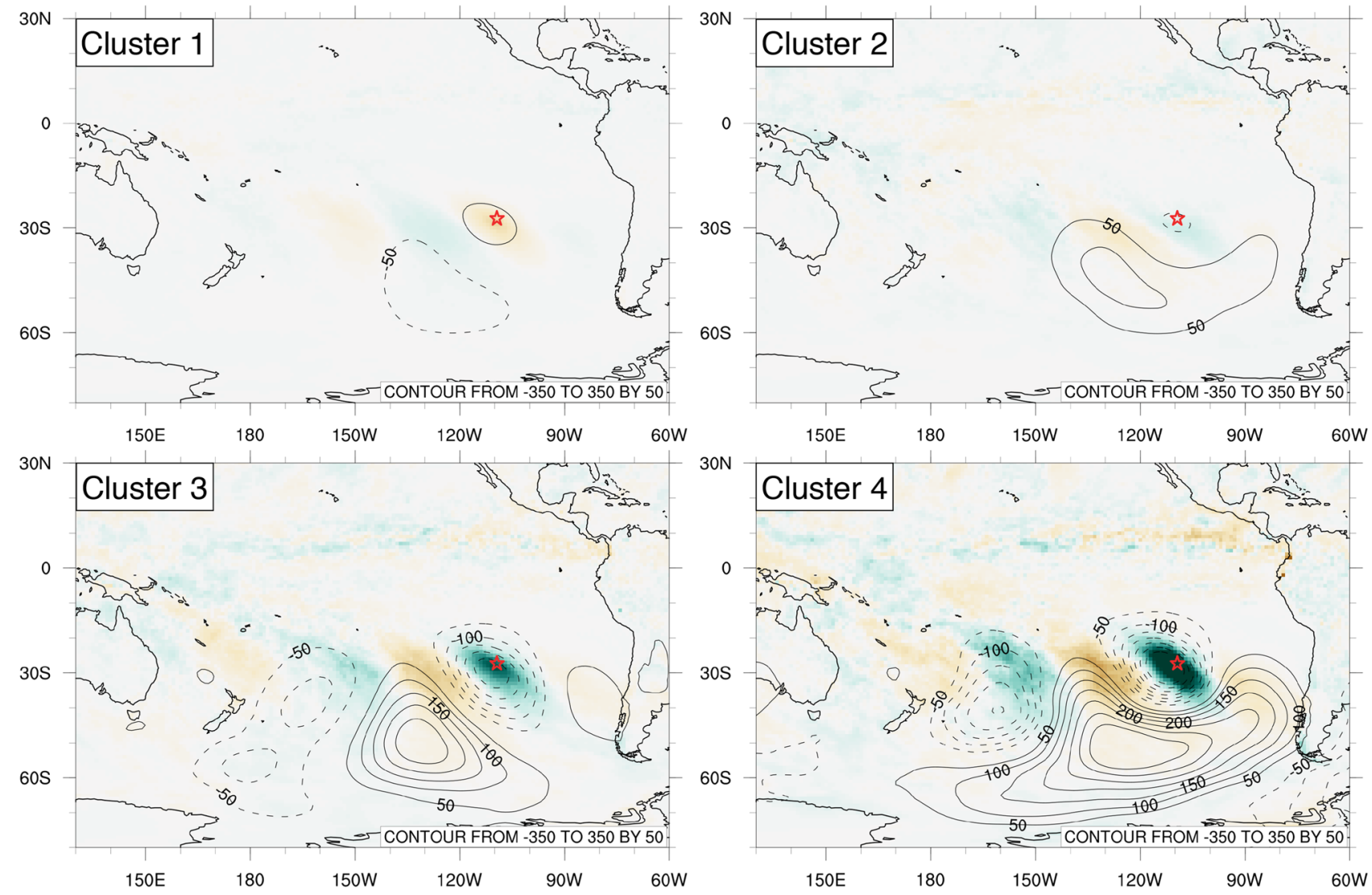

$-4.5-3.6-2.7-1.8-0.9 \quad 0 \quad 0.91 .8 \quad 2.7 \quad 3.6 \quad 4.5$

Precipitation anomaly $(\mathrm{mm})$

Fig. 6 Cluster composites. Composites of daily precipitation anomalies and mean sea level pressure anomalies over all cluster events. Data are from ERA5 and anomalies are with respect to the seasonal cycle. The number of events within each composite is: Cluster $1=$

spatial patterns that allow one to visualize a reduced space summary of the patterns that are present in a dataset. We found that using any more than four integrated water vapor patterns created clear pattern redundancy, though our visualization analysis does not depend critically on the choice of this number of patterns. The four self-organizing map patterns in Fig. 7 show that the underlying atmospheric rivers are oriented in a Northwest-Southeast direction. Composites of $500 \mathrm{hPa}$ geopotential height anomaly fields that are associated with each integrated water vapor pattern (as determined by the self-organizing map algorithm), show that the atmospheric rivers are associated with atmospheric low pressure systems, Fig. 7.

According to our calculation above, synoptic systems other than atmospheric rivers account for two-thirds of Cluster 4 events. As in the atmospheric river analysis, we use self-organizing maps to synoptically classify the
9654, Cluster $2=2801$, Cluster $3=1223$, Cluster $4=567$. The location of Rapa Nui is given by a red star. For clarity of all panels, the positive precipitation anomalies are only shown up to $5 \mathrm{~mm}$ but reach a maximum of $9.5 \mathrm{~mm}$ over Rapa Nui

remaining Cluster 4 events, but compute the patterns based on $500 \mathrm{hPa}$ geopotential height anomaly fields (anomalies with respect to the seasonal cycle), Fig. 8. As in the calculations for Fig. 7, we found that four patterns best represented the range of the underlying potential patterns without clear pattern redundancy. In Fig. 8 we also composite total precipitation and 2-m temperature fields that correspond to each geopotential height pattern. We find that these remaining Cluster 4 events can be categorized into cold-front systems (pattern 3), cut-off lows (pattern 4 and potentially also pattern 2 ), and other general lowpressure systems (pattern 1 and pattern 2), Fig. 8. Of these, the most common is the cold-front pattern 3 , which represents $31 \%$ of the self-organizing map patterns in Fig. 8 and thus $21 \%$ of all Cluster 4 events $(31 * 0.67=20.7 \approx 21 \%)$. Figures 7 and 8 show that no one kind of synoptic system predominates the Cluster 4 large rain events. 


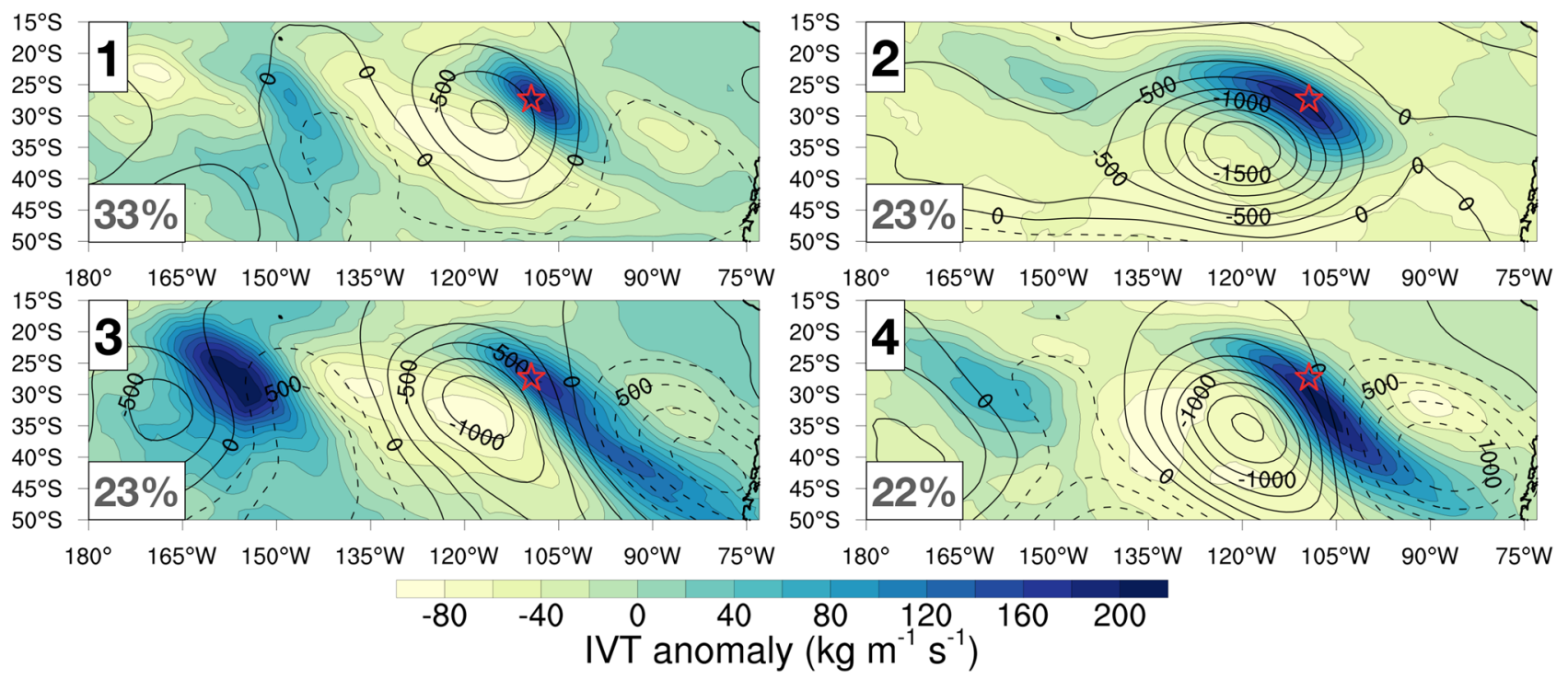

Fig. 7 Cluster 4 atmospheric river events. All atmospheric river events corresponding to Cluster 4 events are partitioned into four fundamental patterns (see text), labeled $1-4$, of the integrated water vapor transport (IVT) fields. Overlaid on top are composites of the $500 \mathrm{hPa}$ geopotential height anomaly fields associated with each IVT pattern, with positive values shown as dashed contours. Both IVT and

\section{Dynamical causes of large rain events}

Given the clear importance of Cluster 4 events, we explored the relationship between these events and a number of phenomena tied to large-scale climate dynamics. Among the many phenomena that we tested (see below), we found that only measures associated with the eastern south Pacific anticyclone were significantly correlated $(\alpha=0.05)$ with the frequency of Cluster 4 events and annual precipitation. We illustrate this climatological anticyclone in Fig. 9a, which shows the annual mean $1020 \mathrm{hPa}$ mean sea level pressure contours from ERA5 for each year from 1979-2017. (We chose the pressure value of $1020 \mathrm{hPa}$ because lower values were not contained within the eastern south Pacific, while higher pressure levels left out some individual years because they did not contain average pressure values above $1020 \mathrm{hPa}$.) There is considerable year-to-year variability in the location and shape of the high-pressure anticyclones. Though the longitudinal variation in the anticyclones dominates the measure of the distance from Rapa Nui (Fig. 9a, b), we find that their absolute distance away from Rapa Nui best explains annual precipitation and Cluster 4 events (Fig. 9c). We also tested the correlation of Cluster 4 events with local mean sea level pressure and the anticyclone pressure maximum, but found that the distance away from the anticyclone centroid was more highly correlated. Dynamically, we interpret these data as the shifting of the location of the "blocking" anticyclone: when the high-pressure anticyclone is on geopotential height fields are shown as anomalies with respect to the seasonal cycle. The frequency of occurrence of each pattern is indicated in the lower left corner of each panel. Note that because each IVT pattern is approximately equal to the composite of the individual underlying fields, the composite averages result in IVT values that are lower than any individual atmospheric river field

average displaced farther westward it blocks storms from raining on Rapa Nui; when the anticyclone is on average displaced eastward, more storms are allowed to pass over Rapa Nui. The positioning of the anticyclone also appears to be the principle factor controlling the "blocking" effect. Unlike the seasonal cycle, we found no evidence that the strength of the anticyclone contributes to annual precipitation variability: in a multivariate regression model, adjusted $-r^{2}$ values decreased relative to a regression model that only used the longitudinal location variable. This indicates that whatever (linear) information is contained in the strength of the anticyclone it is already captured in the metric of the anticyclone centroid distance.

As noted above, we did not find statistically significant relationships between Cluster 4 events and the following phenomena: (1) the SPCZ, including the latitudinal location, the eastward extent, and the linear slope of the SPCZ (as in Vincent et al. 2011) in the wet season, the dry season, and the annual mean; (2) the Southern Annular Mode index (Gong and Wang 1999) over the full Southern Hemisphere as well as the southern Pacific sector for the dry season, the wet season, and the annual mean; (3) the ENSO indices (Niño1+2, Niño3, Niño3.4, and Niño4) at monthly, annual, wet season, and dry season time scales; (4) the latitudinal location of the intertropical convergence zone (Adam et al. 2016) over the global tropics as well as over Indonesia, the west Pacific, the east Pacific, and the full Pacific sectors for the dry season, the wet season, and the annual mean; 

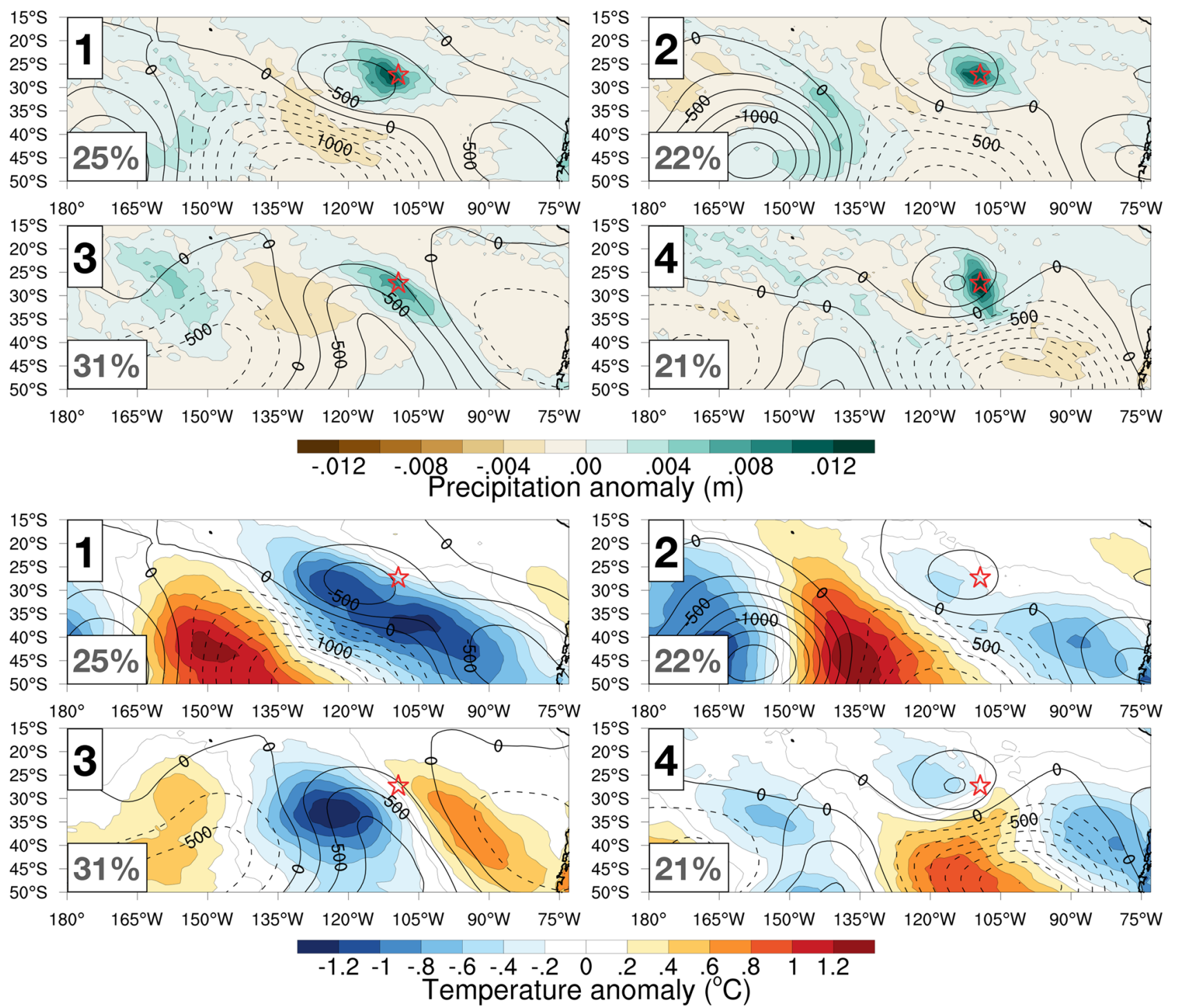

Fig. 8 Non-atmospheric river Cluster 4 event characterization. The top four panels show the four $500 \mathrm{hPa}$ geopotential height contour patterns derived from the self-organizing map calculation (with positive values shown as dashed contours). Along with each geopotential height pattern is a composite of corresponding total precipitation

and (5) the Madden-Julian Oscillation using the OMI index (Kiladis et al. 2013) at the filtered daily time scale as well as at monthly, wet season, and dry season averages. We also tested multivariate relationships between Cluster 4 precipitation and these listed phenomena along with the variable of the longitudinal location of the eastern south Pacific anticyclone (Fig. 9b), but none of the multivariate linear regression models had adjusted $r^{2}$ values greater than an anticycloneonly linear model. While we found no clear linear relationships between these other phenomena and Cluster 4 rain events on Rapa Nui, it may be that a robust relationship could emerge with more data beyond the reanalysis era (e.g., fields. The bottom four panels show the same geopotential height patterns but with $2 \mathrm{~m}$ temperature composites instead of precipitation. The frequency of occurrence of each pattern, within this set of nonatmospheric river events, is indicated in the lower left corner of each panel. All anomalies are with respect to the seasonal cycle

longer observational records or paleoclimatic data). It is also possible that Cluster 4 rain events may be related to other dynamical variables not tested here, such as an explicit calculation of the location and strength of the storm track (and not just the Southern Annular Mode index as tested here).

\section{Discussion and conclusions}

We have analyzed key features of the hydroclimate of Rapa Nui. There is a clear seasonal cycle of precipitation on the island, with the wettest months delivering almost twice as 


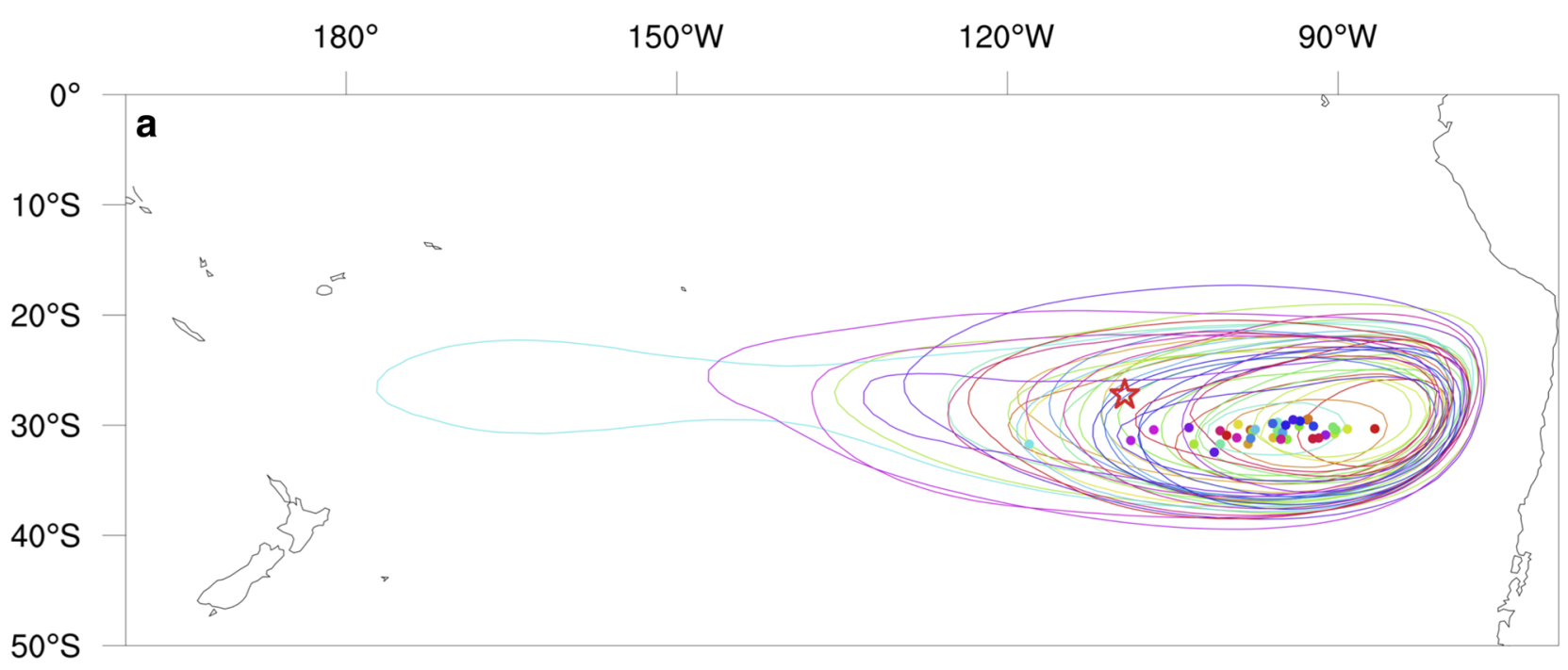

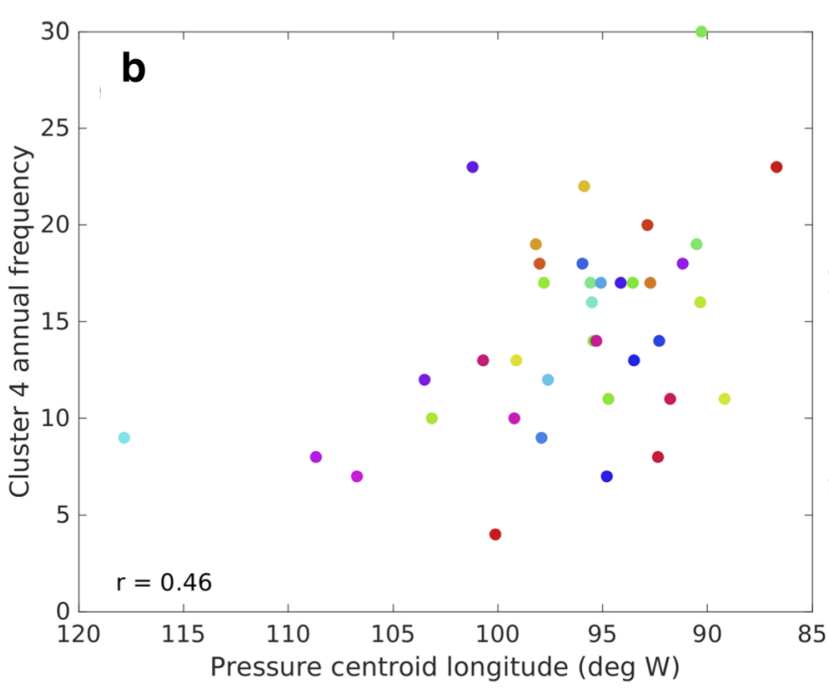

Fig. 9 Pressure dynamics controlling Cluster 4 precipitation events. a Annual mean $1020 \mathrm{hPa}$ mean sea level pressure contour level from 1979-2017. Corresponding colored dots indicate each year's centroid location (center of mass). The location of Rapa Nui is given by a red star. b Scatter plot of the longitude of the centroid locations in (a)

much precipitation as the driest months (Fig. 2). The seasonal cycle of precipitation is caused by seasonal changes in the number of large rain events (Fig. 4d, e). More large rain events occur during the months when the south Pacific subtropical anticyclone is, on average, weakest and farthest away from Rapa Nui (Fig. 2).

Interannual variability in precipitation is almost entirely determined by the number of the largest rain events, which according to our partitioning of the data occur on average about 15 times per year (Figs. 4c, 5). Variability in the number of these large rain events explains $92 \%$ of the variance of annual precipitation on Rapa Nui. These large rain events are not caused by any one particular kind of synoptic system, but occur due to a combination of atmospheric rivers,

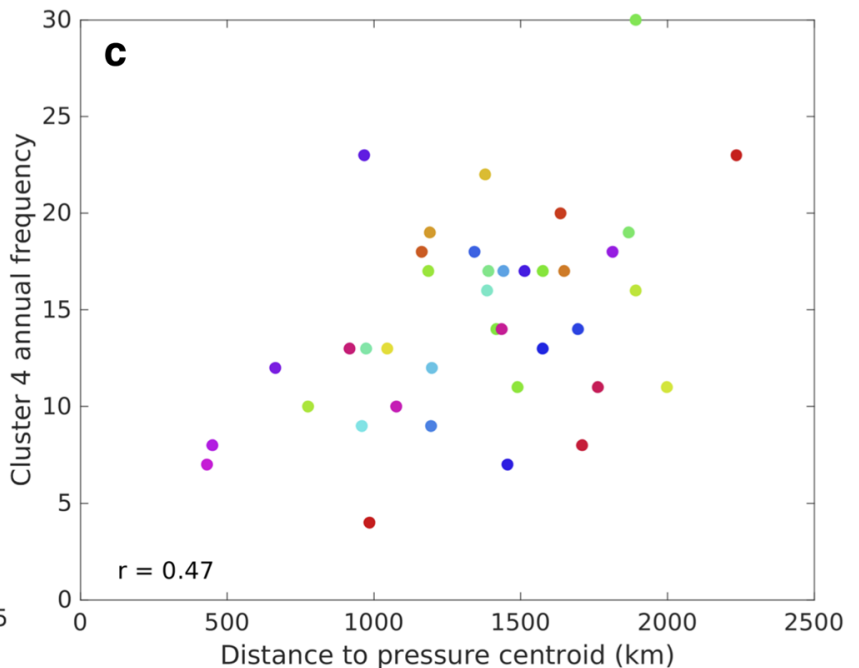

versus the number of Cluster 4 events for each year. Pearson's correlation $r$ is noted in the lower corner. Dot colors in $\mathbf{b}$ match the corresponding lines and dots in (a). c Similar to $\mathbf{b}$, but a scatter plot of the distance separating Rapa Nui and the centroids of the anticyclones

cold-fronts, cut-off lows, and other kinds of low-pressure systems, Figs. 7, 8. The frequency of these storm systems is partially controlled by the longitudinal location of the south Pacific subtropical anticyclone; the average location of the anticyclone can, on average, either block storms from hitting Rapa Nui or allow storms to rain on Rapa Nui by being displaced eastward. This mechanism is similar to the mechanism that controls the seasonal cycle of precipitation, except that we find no additional contribution from the strength of the anticyclone, only its longitudinal position appears to matter. The explanatory power of the anticyclone is nevertheless limited, given that only $21 \%$ of the variance of large rain events (Cluster 4 events) can be explained by the longitudinal location of the anticyclone. We find no statistically 
significant relationship between the interannual variability of these large rain events and large-scale climate phenomena such as the SPCZ, the Southern Annular Mode, ENSO, the intertropical convergence zone, and the Madden-Julian Oscillation. Neither do these phenomena contribute in a statistically significant way to a multivariate explanation. This suggests that the variability of these large rain events may be fundamentally stochastic. Longer time-scale information such as from the paleoclimatic record may help to uncover any additional underlying drivers of the variability of these rain events.

Our findings have important implications for anticipating future hydroclimate conditions on Rapa Nui. The Southern Hemisphere's subtropical anticyclones are projected to strengthen and expand westward under global warming ( $\mathrm{Li}$ et al. 2013; Fahad et al. 2020). Combined with our results, this implies that Rapa Nui will experience an increased number of dry years in the future. Given the increasing freshwater demands on the small island, due to on-going development and growth in tourism, policy makers and resource managers should be aware that a tendency toward drier conditions likely lies ahead. Sedimentary records from the wetlands of Rapa Nui suggest intervals of prolonged drought lasting tens to hundreds of years in recent centuries and millennia (Azizi and Flenley 2008; Mann et al. 2008; Sáez et al. 2009; Margalef et al. 2013). Because the timescales of sedimentary records are much longer than available instrumental records, such paleoclimatic records of drought from Rapa Nui could be very valuable for clarifying the timing and nature of droughts on Rapa Nui and their dynamical causes. This would provide valuable climatic context for both Rapa Nui and the broader region of the south Pacific and western South America.

Acknowledgements We thank Rene Garreaud for directing us to the observational database.

Author Contributions NJS, WJD, and JES designed the experiments, while NJS developed the code, ran the experiments, and analyzed the experimental results. NJS, WJD, and JES prepared the manuscript with assistance from RSB.

Funding This work was supported in part by NSF Grants OISE1743738, EAR-1903676, and AGS-1805490 and ISF Grant 2654/20.

Availability of data and material ERA5 is publicly available from the Copernicus Climate Data Store: https://cds.climate.copernicus. eu/cdsapp\#!/home. Precipitation data for Rapa Nui is available from http://explorador.cr2.cl.

Code Availability Statement The code for computing the analyses presented in this paper is available upon request from the authors.

\section{Declarations}

Conflict of interest The authors declare no competing interests.
Open Access This article is licensed under a Creative Commons Attribution 4.0 International License, which permits use, sharing, adaptation, distribution and reproduction in any medium or format, as long as you give appropriate credit to the original author(s) and the source, provide a link to the Creative Commons licence, and indicate if changes were made. The images or other third party material in this article are included in the article's Creative Commons licence, unless indicated otherwise in a credit line to the material. If material is not included in the article's Creative Commons licence and your intended use is not permitted by statutory regulation or exceeds the permitted use, you will need to obtain permission directly from the copyright holder. To view a copy of this licence, visit http://creativecommons.org/licenses/by/4.0/.

\section{References}

Adam O, Bischoff T, Schneider T (2016) Seasonal and interannual variations of the energy flux equator and ITCZ. part i: Zonally averaged itcz position. J Clim 29(9):3219-3230. https://doi.org/ 10.1175/JCLI-D-15-0512.1

Azizi G, Flenley JR (2008) The last glacial maximum climatic conditions on easter island. Quaternary Int 184(1):166-176. https://doi. org/10.1016/j.quaint.2007.09.027. http://www.sciencedirect.com/ science/article/pii/S1040618207002911

Bony S, Dufresne J-L (2005) Marine boundary layer clouds at the heart of tropical cloud feedback uncertainties in climate models. Geophys Res Lett 32(20). https://doi.org/10.1029/2005GL023851

Bridgman HA (1983) Could climatic change have had an influence on the polynesian migrations? Palaeogeogr Palaeoclimatol Palaeoecol 41(3):193-206. https://doi.org/10.1016/0031-0182(83) 90087-1. http://www.sciencedirect.com/science/article/pii/00310 18283900871

Brosnan T, Becker MW, Lipo CP (2019) Coastal groundwater discharge and the ancient inhabitants of Rapa nui (Easter Island), Chile. Hydrogeol J 27(2):519-534. https://doi.org/10.1007/ s10040-018-1870-7

Cai W, Cowan T, Thatcher M (2012) Rainfall reductions over southern hemisphere semi-arid regions: the role of subtropical dry zone expansion. Sci Rep 2(1):702. https://doi.org/10.1038/srep00702

Cañellas-Boltà N, Coauthors, (2013) Vegetation changes and human settlement of easter island during the last millennia: a multiproxy study of the lake raraku sediments. Quat Sci Rev 72:36-48. https://doi.org/10.1016/j.quascirev.2013.04.004. http://www.scien cedirect.com/science/article/pii/S0277379113001352

Carvajal M, Coauthors (2021) Extreme sea levels at rapa nui (easter island) during intense atmospheric rivers. Nat Hazards 106(2):1619-1637. https://doi.org/10.1007/s11069-020-04462-2

Centro de Ciencias del Clima y la Resiliencia (2019) Explorador climático. http://explorador.cr2.cl

Copernicus Climate Change Service (2019) ERA5: Fifth generation of ECMWF atmospheric reanalyses of the global climate. https:// cds.climate.copernicus.eu/cdsapp\#!/home

Corporación Nacional Forestal (2020) Estadísticas de visitantes nidad snaspe. http://www.conaf.cl/parques-nacionales/visitanos/estad isticas-de-visitacion/

Al Fahad A, Burls NJ, Strasberg Z (2020) How will southern hemisphere subtropical anticyclones respond to global warming? mechanisms and seasonality in cmip5 and cmip6 model projections. Clim Dyn 55(3):703-718. https://doi.org/10.1007/ s00382-020-05290-7

Fahad AA, Burls NJ, Swenson ET, Straus DM (2021) The influence of south pacific convergence zone heating on the south pacific subtropical anticyclone. J Clim 34(10):3787-3798. https://doi.org/10. 1175/JCLI-D-20-0509.1. https://journals.ametsoc.org/view/journ als/clim/34/10/JCLI-D-20-0509.1.xml 
Figueroa EB, Rotarou ES (2016) Sustainable development or eco-collapse: Lessons for tourism and development from easter island. Sustainability 8(11):1093

Genz J, Hunt TL (2003) El nino/southern oscillation and rapa nui prehistory. Rapa Nui J: J Easter Island Found 17(1):7

Gong D, Wang S (1999) Definition of antarctic oscillation index. Geophys Res Lett 26(4):459-462. https://doi.org/10.1029/1999G L900003

He C, Wu B, Zou L, Zhou T (2017) Responses of the summertime subtropical anticyclones to global warming. J Clim30(16):64656479. https://doi.org/10.1175/JCLI-D-16-0529.1. https://journals. ametsoc.org/view/journals/clim/30/16/jcli-d-16-0529.1.xml

Horton DE, Johnson NC, Singh D, Swain DL, Rajaratnam B, Diffenbaugh NS (2015) Contribution of changes in atmospheric circulation patterns to extreme temperature trends. Nature 522:465-469. https:// doi.org/10.1038/nature14550

Hu G, Franzke CLE (2020) Evaluation of daily precipitation extremes in reanalysis and gridded observation-based data sets over germany. Geophys Res Lett 47(18):e2020GL089-624. https://doi.org/10.1029/ 2020GL089624

Jenny B, Wilhelm D, Valero-Garcés B (2003) The southern westerlies in central chile: Holocene precipitation estimates based on a water balance model for laguna aculeo (33오 ). Clim Dyn 20(2):269-280. https://doi.org/10.1007/s00382-002-0267-3

Johnson NC, Feldstein SB, Tremblay B (2008) The continuum of northern hemisphere teleconnection patterns and a description of the nao shift with the use of self-organizing maps. J Clim 21(23):6354 6371. https://doi.org/10.1175/2008JCLI2380.1

Kiladis GN, Dias J, Straub KH, Wheeler MC, Tulich SN, Kikuchi K, Weickmann KM, Ventrice MJ (2013) A comparison of olr and circulation-based indices for tracking the mjo. Mon Weather Rev 142(5):1697-1715. https://doi.org/10.1175/MWR-D-13-00301.1

Kiladis GN, von Storch H, Loon H (1989) Origin of the south pacific convergence zone. J Clim 2(10):1185-1195. https://doi.org/10.1175/ 1520-0442(1989)002<1185:OOTSPC >2.0.CO;2. https://journals. ametsoc.org/view/journals/clim/2/10/1520-0442_1989_002_1185_ ootspc_2_0_co_2.xml

Kilian R, Lamy F (2012) A review of glacial and holocene paleoclimate records from southernmost patagonia $\left(49-55^{\circ} \mathrm{s}\right)$. Qua Sci Rev 53:1-23. https://doi.org/10.1016/j.quascirev.2012.07.017. http:// www.sciencedirect.com/science/article/pii/S0277379112002843

Kohonen T (1998) The self-organizing map. Neurocomputing 21(1):1-6. https://doi.org/10.1016/S0925-2312(98)00030-7. http://www.scien cedirect.com/science/article/pii/S0925231298000307

Ladefoged TN, Flaws A, Stevenson CM (2013) The distribution of rock gardens on rapa nui (easter island) as determined from satellite imagery. J Archaeol Sci 40(2):1203-1212. https://doi.org/10.1016/j. jas.2012.09.006. http://www.sciencedirect.com/science/article/pii/ S0305440312004049

Lamy F, Kilian R, Arz HW, Francois J-P, Kaiser J, Prange M, Steinke T (2010) Holocene changes in the position and intensity of the southern westerly wind belt. Nat Geosci 3(10):695-699. https://doi.org/ 10.1038/ngeo959

Li W, Coauthors (2013) Intensification of the southern hemisphere summertime subtropical anticyclones in a warming climate. Geophys Res Lett 40(22):5959-5964. https://doi.org/10.1002/2013GL058124

Lintner BR, Neelin JD (2008) Eastern margin variability of the south pacific convergence zone. Geophys Res Lett. https://doi.org/10. 1029/2008GL034298,

Mann D, Edwards J, Chase J, Beck W, Reanier R, Mass M, Finney B, Loret J (2008) Drought, vegetation change, and human history on rapa nui (isla de pascua, easter island). Quaternary Res 69(1):16-28. https://doi.org/10.1016/j.yqres.2007.10.009. http://www.sciencedir ect.com/science/article/pii/S003358940700141X

Margalef O, Coauthors, (2013) A 70,000 year multiproxy record of climatic and environmental change from rano aroi peatland (easter island). Glob Planet Change 108:72-84. https://doi.org/10.1016/j. gloplacha.2013.05.016. http://www.sciencedirect.com/science/artic le/pii/S0921818113001410

McCall G (1993) Little ice age, some speculations for rapanui. Rapa Nui J 7(4):65-70

Mieth A, Bork H-R (2010) Humans, climate or introduced rats -which is to blame for the woodland destruction on prehistoric rapa nui (easter island)? J Archaeol Sci 37(2):417-426. https://doi.org/10. 1016/j.jas.2009.10.006. http://www.sciencedirect.com/science/artic le/pii/S0305440309003732

Moreno PI, Lowell TV, Jacobson GL Jr, Denton GH (1999) Abrupt vegetation and climate changes during the last glacial maximumand last termination in the chilean lake district: a case study from canal de la puntilla (41ㅇs). Geografiska Annaler: Ser A Phys Geogr 81(2):285311. https://doi.org/10.1111/1468-0459.00059. https://www.tandf online.com/doi/abs/10.1111/1468-0459.00059

O’Gorman PA, Schneider T (2009) The physical basis for increases in precipitation extremes in simulations of 21 st-century climate change. Proc Natl Acad Sci 106(35), 14 773. https://doi.org/10.1073/ pnas.0907610106. http://www.pnas.org/content/106/35/14773.abstr act

Pierrehumbert RT (1995) Thermostats, radiator fins, and the local runaway greenhouse. J Atmos Sci 52(10):1784-1806. https://doi.org/ 10.1175/1520-0469(1995)052<1784:TRFATL>2.0.CO;2. https:// journals.ametsoc.org/view/journals/atsc/52/10/1520-0469_1995_ 052_1784_trfatl_2_0_co_2.xml

Reid KJ, King AD, Lane TP, Short E (2020) The sensitivity of atmospheric river identification to integrated water vapor transport threshold, resolution, and regridding method. J Geophys Res Atmos 125(20):e2020JD032-897

Rull V, Coauthors (2018) Clafs, a holistic climatic-ecological-anthropogenic hypothesis on easter island's deforestation and cultural change: Proposals and testing prospects. Front Ecol Evolut 6:32. https:// www.frontiersin.org/article/10.3389/fevo.2018.00032

Sáez A, Valero-Garcés BL, Giralt S, Moreno A, Bao R, Pueyo JJ, Hernández A, Casas D (2009) Glacial to holocene climate changes in the se pacific. the raraku lake sedimentary record (easter island, $27^{\circ}$ s). Quat Sci Rev 28(25):2743-2759. https://doi.org/10.1016/j.quasc irev.2009.06.018. http://www.sciencedirect.com/science/article/pii/ S027737910900211X

Seager R, Murtugudde R, Naik N, Clement A, Gordon N, Miller J (2003) Air-sea interaction and the seasonal cycle of the subtropical anticyclones. J Clim 16(12):1948-1966. https://doi.org/10.1175/15200442(2003)016<1948:AIATSC > 2.0.CO;2

Steiger NJ, Smerdon JE, Seager R, Williams AP, Varuolo-Clarke AM (2021) Enso-driven coupled megadroughts in north and south America over the last millennium. Nat Geosci 14(10):739-744. https://doi. org/10.1038/s41561-021-00819-9

Stenseth N, Voje K (2009) Easter island: climate change might have contributed to past cultural and societal changes. Clim Res 39(2):111114. https://www.int-res.com/abstracts/cr/v39/n2/p111-114/

Stevenson CM, Ladefoged T, Haoa S (2002) Productive strategies in an uncertain environment: prehistoric agriculture on easter island. Rapa Nui J: J East Island Found 16(1):4

Takahashi K, Battisti DS (2007) Processes controlling the mean tropical pacific precipitation pattern. part $\mathrm{i}$ : the andes and the eastern pacific itcz. J Clim 20(14):3434-3451

Valero-Garcés BL, Jenny B, Rondanelli M, Delgado-Huertas A, Burns SJ, Veit H, Moreno A (2005) Palaeohydrology of laguna de tagua tagua $\left(34^{\circ} \mathrm{s}\right)$ and moisture fluctuations in central Chile for the last 46 000 yr. J Quat Sci 20(7-8):625-641. https://doi.org/10.1002/jqs.988

Van Der Wiel K, Matthews AJ, Joshi MM, Stevens DP (2016) Why the south pacific convergence zone is diagonal. Clim Dyn 46(5-6):1683-1698

Vincent DG (1994) The south pacific convergence zone (spcz): a review. Monthly Weather Rev 122(9):1949-1970. https://doi.org/10.1175/ 
1520-0493(1994)122<1949:TSPCZA>2.0.CO;2. https://journals. ametsoc.org/view/journals/mwre/122/9/1520-0493_1994_122_ 1949_tspcza_2_0_co_2.xml

Vincent EM, Lengaigne M, Menkes CE, Jourdain NC, Marchesiello P, Madec G (2011) Interannual variability of the south pacific convergence zone and implications for tropical cyclone genesis. Clim Dyn 36(9):1881-1896. https://doi.org/10.1007/s00382-009-0716-3
Publisher's Note Springer Nature remains neutral with regard to jurisdictional claims in published maps and institutional affiliations. 